\title{
BORO EM SOLOS DE VÁRZEA DO SUL DE MINAS GERAIS E A CULTURA DO FEIJOEIRO' ${ }^{1}$
}

\author{
Eduardo Dol'ava Mariano2; Valdemar Faquin ${ }^{3,6 *}$; Antonio Eduardo Furtini Neto ${ }^{3,6}$; Isabela \\ Orlando dos Santos Mariano ${ }^{4}$; Antonio Claret de Oliveira Jr. ${ }^{5}$ \\ ${ }^{2}$ R. Paulo de Oliveira Lima, 351/204 - CEP: 37200-000 - Lavras, MG. \\ ${ }^{3}$ Depto. de Ciência do Solo - UFLA, C.P. 37 - CEP: 37200-000 - Lavras, MG. \\ ${ }^{4}$ Pós-Graduanda do Depto. de Ciência do Solo - UFLA. \\ ${ }^{5}$ Graduando em Engenharia Agronômica - UFLA. \\ ${ }^{6}$ Bolsista do CNPq. \\ *e-mail: vafaquin@ufla.br
}

RESUMO: Com o objetivo de avaliar a resposta do feijoeiro (Phaseolus vulgaris L.) à aplicação de $B$ em solos de várzea, conduziu-se um experimento em casa de vegetação com quatro solos $(0-20 \mathrm{~cm})$, Glei Pouco Húmico (GP), Aluvial (A), Glei Húmico (GH) e Orgânico (O), este último artificialmente drenado, coletados no município de Lavras (MG). O delineamento experimental foi inteiramente casualizado, com quatro repetições, arranjado num esquema fatorial $4 \times 7$, consistindo dos 4 solos e de 7 doses de $B$ $\left(0,0 ; 0,25 ; 0,5 ; 1,5 ; 3,0 ; 6,0\right.$ e $10,0 \mathrm{mg} \mathrm{dm}^{-3}$ de solo). Os solos receberam calcário dolomítico, macro e micronutrientes e as respectivas doses de $B$, e foram incubados por 24 dias. Antes da semeadura, os solos foram amostrados e analisados para B (água quente). Foram cultivadas duas plantas por vaso de três $\mathrm{dm}^{3}$, colhidas na maturação de grãos, avaliando-se a matéria seca de grãos, o número de vagens por planta e o número de grãos por vagem. Os resultados mostraram respostas significativas do feijoeiro à aplicação de $B$ nos solos estudados. As doses de $B$ para atingir $90 \%$ da produção máxima variaram de 1,04 a $1,25 \mathrm{mg} \mathrm{dm}^{-3}$. Para a produção máxima, as doses variaram de 2,50 a $2,83 \mathrm{mg} \mathrm{dm}^{-3}$, enquanto que para causar redução de $10 \%$ na produção, devido a toxidez, a variação na dose de boro foi de 4,54 a $5,33 \mathrm{mg} \mathrm{dm}^{-3}$. O potencial produtivo dos solos para $90 \%$ da produção máxima, em ordem decrescente, foi a seguinte: Glei Húmico > Aluvial = Orgânico > Glei Pouco Húmico.

Palavras-chave: Phaseolus vulgaris, feijão, boro, solo de várzea

\section{BORON IN LOWLAND SOILS FROM SOUTHERN MINAS GERAIS, BRAZIL, IN RELATION TO THE COMMON BEAN CROP}

ABTRACT: Aiming to evaluate the bean (Phaseolus vulgaris L.) plant response to boron application in lowland soils, an experiment was conducted in greenhouse conditions, involving four soils $(0-20 \mathrm{~cm})$, Low Humic Glei (LHG), Aluvial (A), Humic Gley (HG) and Bog soil (O), the last being artificially drained, all collected in Lavras, MG, Brazil. The experimental design was totally randomized, with four replications, in a $4 \times 7$ factorial scheme, consisting of the 4 soils and of $7 \mathrm{~B}$ doses $(0 ; 0.25 ; 0.5 ; 1.5 ; 3.0 ; 6.0$ and $10.0 \mathrm{mg} \mathrm{dm}^{-3}$ ). The soils received dolomitic lime, macro and micronutrients, and the respective doses of $B$, and were incubated for 24 days. Before seeding, the soils were sampled and analysed for B (hot water). Two plants were cultivated in $3 \mathrm{dm}^{3}$ pots; at grain maturation the plants were harvested and the dry matter of grains, the number of pods per plant, and the number of grains per pod were evaluated. The results showed significant responses of the bean plant to the applied boron. The $B$ doses, promoting $90 \%$ of the maximum yield, varied from 1.04 to 1.25 ; for maximum yield, varied from 2.50 to 2.85 ; and for $10 \%$ reduction of the yield due to toxicity, varied from 4.54 to $5.33 \mathrm{mg} \mathrm{dm}^{-3}$. The ranking of the productive potential of the soils for $90 \%$ of the maximum yield was the following: Humic Gley $>$ Aluvial $=$ Bog $>$ Low Humic Gley.

Key words: Phaseolus vulgaris, bean, boron, lowland soil

INTRODUÇÃO

O feijoeiro (Phaseolus vulgaris L.) é uma cultura tradicional no sul de Minas Gerais, praticada, geralmente, por pequenos produtores em solos de baixa fertilidade natural.

${ }^{1}$ Parte da Dissertação de Mestrado apresentada pelo primeiro autor à UFLA - Lavras, MG; Trabalho apresentado na FertBIO’ 98, Caxambú, 1998. 
Ultimamente, seu cultivo vem sendo preconizado nas várzeas como uma boa alternativa para expansão da fronteira agrícola, incorporando áreas cujo aproveitamento tem se limitado quase que exclusivamente ao cultivo do arroz irrigado por inundação contínua.

Como a maioria dos solos brasileiros, os solos de várzea apresentam problemas relativos à fertilidade (Fageria et al., 1996), tornando-se imprescindível conhecer a capacidade dos mesmos em suprir nutrientes às plantas bem como aprimorar-se as recomendações de adubação, visando uma produção eficiente e sustentável ao longo dos anos.

O boro (B) e o zinco (Zn) são os micronutrientes que mais problemas de deficiência têm causado em culturas brasileiras. A baixa fertilidade de alguns solos, maior remoção pelas colheitas e uso crescente de calcário e adubos fosfatados são fatores que contribuem para maior insolubilização de micronutrientes (Bataglia \& Raij, 1989). De acordo com Marschner (1995), as dicotiledôneas - dentre elas o feijoeiro - apresentam um maior requerimento de $B$ quando comparado com as monocotiledôneas. Esse fato justifica a maior freqüência do aparecimento de deficiência de $B$ em cultivos de espécies dicotiledôneas, as quais exigem uma maior atenção no suprimento desse micronutriente.

Respostas significativas à adição de $\mathrm{B}$ têm sido obtidas em diversos tipos de solos, culturas e estados, citando-se especificamente para o feijoeiro em solos de várzea, os trabalhos de Ruschel et al. (1970) e Andrade (1997). Entretanto, há falta de definições sobre métodos analíticos para avaliar a sua disponibilidade em diferentes tipos de solos e, principalmente, de limites de interpretação, que permitam recomen-dações seguras de doses adequadas às diferentes culturas. Mais recentemente, no Estado de São Paulo (Raij et al., 1996), recomenda-se para o feijoeiro a aplicação de $1,0 \mathrm{~kg}$ de $B \mathrm{ha}^{-1}$, quando o teor de $\mathrm{B}$ no solo extraído com água quente for inferior a $0,21 \mathrm{mg}$ $\mathrm{dm}^{-3}$, independente do tipo de solo.

Contudo, a grande heterogeneidade dos solos de várzea, tem mostrado que não se pode generalizar os problemas nutricionais e respostas ao fornecimento de $\mathrm{B}$ e outros micronutrientes nesses sistemas, pois eles são dependentes do tipo de solo e da cultura em questão (Galrão, 1990; Paula et al., 1990). Aliado a esses aspectos, a existência de um limite estreito entre as concentrações adequadas e tóxicas de $B$ nas plantas, exige um planejamento cuidadoso de fertilização com o micronutriente.
O objetivo desse trabalho foi avaliar 0 potencial de quatro solos de várzea para produção do feijoeiro e a resposta da cultura à aplicação de doses de B.

\section{MATERIAL E MÉTODOS}

O experimento foi conduzido em casa de vegetação no Departamento de Ciência do Solo da Universidade Federal de Lavras, Lavras, MG, utilizando vasos plásticos com capacidade para três $\mathrm{dm}^{3}$. Utilizaram-se amostras de quatro solos de várzea não cultivados anteriormente: Aluvial (A), Glei Pouco Húmico (GP), Glei Húmico $(\mathrm{GH})$ e Orgânico $(\mathrm{O})$, esse último artificialmente drenado.

As amostras dos solos foram coletadas da camada superficial $(0-20 \mathrm{~cm})$, em uma várzea não sistematizada no município de Lavras, MG, secas e passadas em peneira com malha de $5 \mathrm{~mm}$ de abertura. Sub-amostras foram tomadas para caracterização química, física e mineralógica.

A granulometria dos solos foi determinada pelo método da pipeta (Day, 1965) após queima da matéria orgânica com peróxido de hidrogênio concentrado. Para a densidade do solo (Ds) utilizou-se o método do anel volumétrico, segundo Blake (1965), e para a densidade de partículas $(\mathrm{Dp})$ o método do balão volumétrico, com álcool etílico (Empresa Brasileira de Pesquisa Agropecuária, 1979). A superfície específica foi determinada pelo método do etileno-glicol-monoetil-éter (EMEG) de Heilman et al. (1965), óxidos pelo ataque sulfúrico $\left(\mathrm{SiO}_{2}, \mathrm{Al}_{2} \mathrm{O}_{3}, \mathrm{Fe}_{2} \mathrm{O}_{3}, \mathrm{TiO}_{2}\right.$ e $\left.\mathrm{P}_{2} \mathrm{O}_{5}\right)$ e pH em água, $\mathrm{Ca}, \mathrm{Mg}, \mathrm{Al}, \mathrm{P}$ e $\mathrm{K}$ determinados conforme Vettori (1969) com modificações (EMBRAPA, 1979). O B disponível nos solos foi extraído com água quente (Berger \& Truog, 1939) e determinado no extrato com o uso de azometina-H (Malavolta et al., 1997). Também foram realizadas as determinações da acidez potencial $(\mathrm{H}+\mathrm{Al})$ e do carbono orgânico conforme Raij et al. (1987) e do Zn com - extrator DTPA. Na fração argila foram quantificadas caulinita e gibbsita através de análise termo-diferencial (ATD) e óxidos de ferro livre $\left(\mathrm{Fe}_{\mathrm{d}}\right)$, usando o ditionito-citrato-bicarbonato de sódio (DCB) (Mehra \& Jackson, 1960) (TABELA 1).

O experimento foi arranjado num esquema fatorial $4 \times 7$, com quatro repetições, sendo os fatores: 4 solos (GP, A, GH e O) e 7 doses de $B(0,0 ; 0,25 ; 0,5 ; 1,5 ; 3,0 ; 6,0$ e $10,0 \mathrm{mg} \mathrm{dm}^{-3}$ de solo), em delineamento inteiramente casualizado. 
TABELA 1 - Atributos químicos, físicos e mineralógicos dos solos de várzea usados no experimento.

\begin{tabular}{|c|c|c|c|c|c|c|c|c|c|c|c|c|c|c|}
\hline \multicolumn{15}{|c|}{ Químicos² } \\
\hline Solo ${ }^{1}$ & $\mathrm{pH}$ & $\mathrm{P}$ & $\mathrm{K}$ & B & $\mathrm{Zn}$ & $\mathrm{Ca}$ & $\mathrm{Mg}$ & $\mathrm{Al}$ & $\mathrm{H}+\mathrm{Al}$ & $\mathrm{S}$ & $\mathrm{t}$ & $\mathrm{T}$ & $\mathrm{m}$ & $\mathrm{V}$ \\
\hline & & \multicolumn{4}{|c|}{-------- $\mathrm{mg} \mathrm{dm}^{-3}$-------- } & \multicolumn{7}{|c|}{ - } & \multicolumn{2}{|c|}{--- \% --- } \\
\hline GP & 5,3 & 3 & 36 & 0,18 & 1,2 & 0,6 & 0,2 & 1,1 & 6,3 & 0,9 & 2,0 & 7,2 & 55 & 12 \\
\hline A & 5,2 & 3 & 103 & 0,23 & 2,4 & 2,7 & 1,1 & 0,2 & 4,5 & 4,1 & 4,3 & 8,6 & 5 & 47 \\
\hline GH & 5,4 & 8 & 51 & 0,21 & 2,1 & 0,7 & 0,2 & 1,6 & 13,7 & 1,0 & 2,6 & 14,7 & 61 & 7 \\
\hline 0 & 5,4 & 6 & 76 & 0,16 & 1,9 & 1,6 & 1,2 & 0,9 & 9,8 & 3,0 & 3,9 & 12,8 & 23 & 23 \\
\hline
\end{tabular}

Físicos ${ }^{3}$

\begin{tabular}{|c|c|c|c|c|c|c|c|c|}
\hline & Areia grossa & Areia fina & Silte & Argila & Matéria orgânica & Ds & $\mathrm{Dp}$ & Superfície específica \\
\hline & \multicolumn{5}{|c|}{ 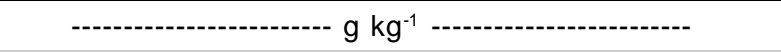 } & \multicolumn{2}{|c|}{$--\mathrm{g} \mathrm{cm}^{-3}--$} & ------ $\mathrm{m}^{2} \mathrm{~g}^{-1}------$ \\
\hline GP & 29 & 592 & 174 & 174 & 31 & 1,05 & 2,66 & 120,8 \\
\hline A & 0 & 174 & 456 & 339 & 31 & 0,76 & 2,77 & 137,4 \\
\hline $\mathrm{GH}$ & 8 & 177 & 300 & 285 & 230 & 0,40 & 1,81 & 334,6 \\
\hline $\mathrm{O}$ & 0 & 115 & 545 & 296 & 44 & 0,64 & 2,15 & 180,7 \\
\hline
\end{tabular}

\begin{tabular}{lcccccccc}
\hline \multicolumn{7}{c}{ Mineralógicos $^{4}$} \\
\hline & $\mathrm{SiO}_{2}$ & $\mathrm{Al}_{2} \mathrm{O}_{3}$ & $\mathrm{Fe}_{2} \mathrm{O}_{3}$ & $\mathrm{TiO}_{2}$ & $\mathrm{P}_{2} \mathrm{O}_{5}$ & $\mathrm{Fe}_{\mathrm{d}}$ & Caulinita & Gibbsita \\
\hline & $-112,2$ & 13,0 & 6,2 & 0,10 & 3,2 & 64,9 & 19,0 \\
$\mathrm{GP}$ & 84,2 & 11,0 & \\
$\mathrm{~A}$ & 209,3 & 221,1 & 74,5 & 9,3 & 0,51 & 41,8 & 145,1 & 49,2 \\
$\mathrm{GH}$ & 126,1 & 175,5 & 13,3 & 5,5 & 1,52 & 6,5 & 48,7 & 53,6 \\
$\mathrm{O}$ & 243,4 & 247,1 & 42,8 & 7,3 & 0,48 & 15,7 & 119,3 & 56,8 \\
\hline
\end{tabular}

${ }^{1} \mathrm{GP}=$ Glei Pouco Húmico, $\mathrm{A}=$ Aluvial, $\mathrm{GH}=$ Glei Húmico e $\mathrm{O}=$ Orgânico. ${ }^{2} \mathrm{~S}=$ soma de bases, $\mathrm{t}=\mathrm{CTC}$ efetiva, $\mathrm{T}=\mathrm{CTC}$ potencial, $\mathrm{m}=$ saturação por $\mathrm{Al}, \mathrm{V}=$ saturação por bases. ${ }^{3} \mathrm{Ds}=$ densidade do solo, $\mathrm{Dp}$ $=$ densidade de partículas. ${ }^{4} \mathrm{Fe}_{\mathrm{d}}=$ óxidos de ferro livre pelo ditionito - citrato - bicarbonato de sódio.

A correção da acidez dos solos, bem como o fornecimento de $\mathrm{Ca}$ e $\mathrm{Mg}$ foram feitos com o uso de calcário dolomítico calcinado, com $36 \%$ de $\mathrm{CaO}, 14 \%$ de $\mathrm{MgO}$ e PRNT $=100 \%$, nas doses 13,$4 ; 4,6 ; 6,4$ e $4,6 \mathrm{t} \mathrm{ha}^{-1}$, para os solos GP, A, GH e O, respectivamente, conforme Andrade (1997).

Os solos receberam como adubação básica de semeadura: $70 \mathrm{mg}$ de $\mathrm{N} ; 300 \mathrm{mg}$ de $\mathrm{P} ; 100 \mathrm{mg}$ de $\mathrm{K} ; 40 \mathrm{mg}$ de S; $1,5 \mathrm{mg}$ de $\mathrm{Cu}$ e $5,0 \mathrm{mg}$ de $\mathrm{Zn} \mathrm{dm}^{-3}$ de solo e as respectivas doses de $\mathrm{B}$, na forma de ácido bórico p.a. $\left(\mathrm{H}_{3} \mathrm{BO}_{3}\right)$. As fontes utilizadas foram sais p.a.: $\mathrm{Ca}\left(\mathrm{H}_{2} \mathrm{PO}_{4}\right)_{2} .2 \mathrm{H}_{2} \mathrm{O} ; \quad \mathrm{KH}_{2} \mathrm{PO}_{4} ; \quad \mathrm{NH}_{4} \mathrm{H}_{2} \mathrm{PO}_{4}$; $\mathrm{CaSO}_{4} .2 \mathrm{H}_{2} \mathrm{O} ; \mathrm{ZnSO}_{4} .7 \mathrm{H}_{2} \mathrm{O} ; \mathrm{CuSO}_{4} .5 \mathrm{H}_{2} \mathrm{O}$; $\left(\mathrm{NH}_{4}\right)_{2} \mathrm{SO}_{4} ; \mathrm{NH}_{4} \mathrm{NO}_{3}$ e $\mathrm{KNO}_{3}$.

Os solos foram incubados em sacos plásticos durante 24 dias, mantendo-se a umi- dade correspondente a $70 \%$ do Volume Total de Poros (VTP) ocupados por água. Após a incubação e antes da semeadura, os solos foram amostrados e analisados para B (água quente).

Cultivou-se o feijoeiro (Phaseolus vulgaris L. cv. Carioca-MG) no período de 6 de maio a 16 de agosto de 1997, conduzindo-se duas plantas por vaso. A umidade dos solos foi mantida em torno de $70 \%$ do VTP, por meio de pesagens diárias dos vasos e adição de água deionizada.

Foram realizadas adubações em cobertura com $\mathrm{N}$ e $\mathrm{K}$, diferenciadas em função do crescimento das plantas. Os tratamentos que proporcionaram um crescimento normal das plantas, receberam $110 \mathrm{mg}$ de $\mathrm{N}$ e $70 \mathrm{mg}$ de $\mathrm{K}$ $\mathrm{dm}^{-3}$ de solo, parcelados em três aplicações. Os 
tratamentos cujas plantas apresentaram menor crescimento receberam coberturas proporcionalmente menores, evitando-se, assim, aplicações excessivas dos nutrientes.

As plantas foram colhidas na maturação fisiológica dos grãos (estádio R9), e após secagem em estufa a $65-70^{\circ} \mathrm{C}$, determinou-se o peso da matéria seca de grãos, o número de vagens por planta e o número de grãos por vagem.

Os dados obtidos foram submetidos a análise de variância e de regressão. Equações de regressão foram ajustadas para o peso da matéria seca de grãos, número de vagens por planta e número de grãos por vagem, em função das doses de B aplicadas. A partir das equações obtidas, estimaram-se as doses de B para a produção máxima, $90 \%$ da máxima (dose inferior) e aquela suficiente para promover por toxidez, uma redução de $10 \%$ na produção (dose superior), para cada solo.

\section{RESULTADOS E DISCUSSÃO}

O teor de B dos solos (água quente), após incubação com as doses aplicadas (TABELA 2) variou entre os solos, mostrando influência dos seus atributos na disponibilidade do micronutriente. Verifica-se que após a incubação, os teores de B na dose 0 (zero), apresentaram-se em valores maiores que os observados nos solos nas condições naturais (TABELA 1), principalmente no solo $\mathrm{GH}$, com o maior teor de matéria orgânica. Este fato, certamente, deve-se à mineralização da matéria orgânica durante o período de incubação. De acordo com Malavolta (1980), a matéria orgânica é a principal fonte de $B$ no solo e a calagem adequada, aumentando a atividade micro- biológica, tende a aumentar a sua disponibilidade; o que concorda com os dados da TABELA 2, onde o teor de $\mathrm{B}$ disponível no solo $\mathrm{GH}$, foi maior em todas as doses aplicadas à exceção da dose mais elevada, embora as médias não tenham sido comparadas estatisticamente. Outros fatores químicos, físicos e mineralógicos, também afetam a disponibilidade de $B$ nos solos (Elrashidi \& O'Connor, 1982). Maiores teores de argila (Biggar \& Fireman, 1960; Gupta, 1968), de óxidos de Fe e Al (Hingston, 1964; Hatcher et al., 1967), com maior afinidade para os óxidos hidratados de $\mathrm{Al}$ (Malcolm et al., 1972), contribuem na adsorção do $B$, reduzindo sua disponibilidade. Mas de acordo com Olson \& Berger (1964), Bingham et al. (1971) e Schalscha et al. (1973), estudando diversos tipos de solos, a adsorção de B é relativamente pequena na faixa de $\mathrm{pH}$ de 4,0 a 7,0 , aumentando na faixa alcalina. No presente estudo, após a incubação com as doses de calcário, os solos apresentaram $\mathrm{pH}$ em água variando de 5,8 a 6,3. Assim, os maiores teores de $B$ observados no solo GH (TABELA 2), certamente, como já discutido, foram devido ao seu maior teor de matéria orgânica, com menor influência dos demais atributos.

A análise de variância para matéria seca de grãos (MSGR), número de vagens por planta (VGPL) e número de grãos por vagem (GRVG) mostrou que os solos $e$ as doses de $B$ influenciaram significativamente $(P<0,01)$ tais variáveis, à exceção dos solos para VGPL, enquanto que a interação doses $x$ solos só não foi significativa para a variável GRVG.

A resposta encontrada nas variáveis avaliadas, era esperada, uma vez que os solos utilizados no experimento, em condições de fertilidade natural, apresentam teores baixos a médios de $B$ (exceção para $0 \mathrm{GH}$ após

TABELA 2 - Teores de B disponível em água quente, após a incubação dos solos com as doses de B, calcário e adubação básica, antes da semeadura do feijoeiro.

\begin{tabular}{lccccccc}
\hline \multicolumn{7}{c}{ Doses de B $\left(\mathrm{mg} \mathrm{dm}^{3}\right)$} \\
\hline Solo $^{1}$ & 0 & 0,25 & 0,50 & 1,50 & 3,00 & 6,00 & 10,00 \\
\hline GP & 0,39 & 0,31 & 0,52 & 0,78 & 2,09 & 3,66 & 6,39 \\
A & 0,29 & 0,38 & 0,49 & 0,84 & 1,56 & 3,57 & 5,52 \\
GH & 0,86 & 1,06 & 0,92 & 1,44 & 2,11 & 4,25 & 6,05 \\
O & 0,35 & 0,42 & 0,50 & 0,94 & 1,91 & 3,94 & 6,33 \\
\hline
\end{tabular}

${ }^{1} \mathrm{GP}=$ Glei Pouco Húmico, A = Aluvial, GH = Glei Húmico e O = Orgânico 
incubação), conforme as classes de fertilidade para $B$ extraído em água quente estabelecidas por Raij et al. (1996). Os autores, generalizando para tipos de solos e culturas, citam como níveis baixos aqueles menores que 0,21, médios - de 0,21 a 0,6 e altos maiores que $0,6 \mathrm{mg}$ de $\mathrm{B} \mathrm{dm}{ }^{-3}$. Após a incubação, os teores de $B$ nos solos estudados, com exceção do $\mathrm{GH}$, também estão abaixo da faixa considerada crítica por Lopes \& Carvalho (1988) $\left(0,4\right.$ a 0,6 $\mathrm{mg} \mathrm{dm}^{-3}$, em água quente) para o desenvolvimento de culturas em geral.

Para todos os solos as equações quadráticas base raiz quadrada foram as que melhor se ajustaram para explicar a relação entre a produção de grãos e as doses de B (Figura 1). O modelo indica aumentos significativos na produção de grãos com a aplicação das doses iniciais de $B$. Após atingir um ponto máximo, a produção decresce nas doses mais altas de $\mathrm{B}$, em conseqüência do efeito tóxico do micronutriente. Portanto, as menores produções de MSGR observadas nas doses 0 (zero) e 10,0 mg de B $\mathrm{dm}^{-3}$, são explicadas pela deficiência e toxicidade de $B$, respectivamente, caracterizadas pelo aparecimento de sintomas típicos de carência e excesso do micronutriente nas plantas. Esse padrão de resposta sugere grande comprometimento na produção de grãos em solos com baixo teor de B disponível, bem como sob aplicação de altas doses do micronutriente. Usando a técnica do elemento faltante, Andrade (1997) verificou que o $B$ quando omitido da adubação, foi o nutriente mais limitante para a produção do feijoeiro cultivado nos mesmos solos de várzea do presente trabalho. $\mathrm{O}$ autor relata que a deficiência de $B$ foi tão drástica que, além da redução do crescimento da parte aérea e dos sintomas típicos de deficiência observados nas plantas, não houve produção de grãos em nenhum dos solos. Cita também que o crescimento e a produção foram normalizados com a aplicação de $0,5 \mathrm{mg} \mathrm{de} \mathrm{B} \mathrm{dm}^{-3}$.

A partir das equações da Figura 1, estimaram-se as produções de MSGR e as doses de $\mathrm{B}$ correspondentes à produção máxima, $90 \%$ da máxima (zona de deficiência) e redução de $10 \%$ da máxima (zona de toxidez) (TABELA 3). No índice de $90 \%$ da produção máxima, estimase representar a máxima eficiência econômica (Alvarez V. et al., 1988).

As doses de $B$ que proporcionaram a máxima produção de MSGR não apresentaram grandes variações entre os solos, oscilando entre 2,50 e $2,83 \mathrm{mg} \mathrm{dm}^{-3}$. Da mesma forma, as doses necessárias para atingir $90 \%$ da produção máxima de MSGR, tanto na zona de deficiência

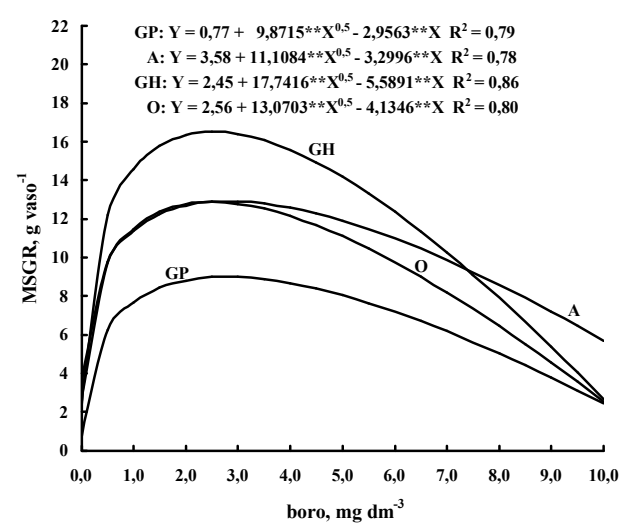

Figura 1 - Produção de matéria seca de grãos (MSGR) pelo feijoeiro em função das doses de B aplicadas aos solos de várzea (** significativo a $1 \%$ pelo teste t).

TABELA 3 - Produção estimada de matéria seca de grãos (MSGR) correspondente à produção máxima e $90 \%$ da máxima e as doses de $B$ estimadas para promover essas produções e redução de $10 \%$ da máxima.

\begin{tabular}{lrrrrrr}
\hline & \multicolumn{2}{c}{ MSGR $\left(\mathrm{g} \mathrm{vaso}^{-1}\right)$} & & \multicolumn{2}{c}{ Dose de $\mathrm{B}\left(\mathrm{mg} \mathrm{dm}^{-3}\right)$} \\
\cline { 2 - 3 } \cline { 6 - 7 } Solo $^{1}$ & $90 \%$ & máxima & & $90 \%$ & \multicolumn{3}{c}{ máxima } & $10 \%$ \\
\hline GP & 8,11 & 9,01 & & 1,25 & 2,79 & 4,94 \\
A & 11,64 & 12,93 & & 1,12 & 2,83 & 5,33 \\
GH & 14,88 & 16,53 & & 1,09 & 2,52 & 4,54 \\
O & 11,61 & 12,90 & & 1,04 & 2,50 & 4,58 \\
\hline
\end{tabular}

${ }^{1} \mathrm{GP}=$ Glei Pouco Húmico, A = Aluvial, GH = Glei Húmico e $\mathrm{O}$ = Orgânico.

quanto na zona de toxidez, tiveram pequena variação entre os solos (TABELA 3).

As doses de $\mathrm{B}$ correspondentes a $90 \%$ da máxima MSGR indicam uma redução média de $58 \%$ das quantidades necessárias para se atingir a produção máxima nos solos. Essa grande redução na dose do nutriente é acompanhada de uma redução de apenas $10 \%$ da produção, representando, assim, uma considerável economia com a adubação e diminuição da relação custo/benefício. Por outro lado, as doses de $\mathrm{B}$ necessárias para reduzir em $10 \%$ a produção máxima de MSGR pelo efeito tóxico do micronutriente, foram, em média, $82 \%$ superiores às doses estimadas para alcançar a 
produção máxima. Estes valores médios representam bem a variação das doses estimadas, uma vez que elas foram semelhantes entre os solos, nos três pontos estudados da curva de produção (TABELA 3).

Os dados (Figura 1 e TABELA 3) mostram que o solo $\mathrm{GH}$ foi o que proporcionou maior produção de MSGR, seguido pelos solos $A$ e $O$, que tiveram produções semelhantes, e pelo GP que apresentou a menor produção de grãos. Possivelmente, o maior teor de matéria orgânica, pelo seu papel como condicionador de solo, tenha propiciado melhores condições para o desenvolvimento das plantas no $\mathrm{GH}$, o que conferiu-lhe maior potencial de produção.

Este resultado não concorda com o de Andrade (1997), que estudando as limitações de fertilidade desses solos, encontrou a seguinte seqüência para produção de grãos: $\mathrm{O}>\mathrm{GH}>$ GP > A, ou seja, o solo $O$, quando corrigido e adubado, apresentou o melhor potencial para a produção do feijoeiro.

Sabe-se que a nutrição da planta está estreitamente relacionada com o seu potencial produtivo, principalmente a nutrição $\operatorname{com} B$, devido a sua participação no processo de fertilização (Faquin, 1994). Apesar do número de vagens por planta e grãos por vagem serem características controladas geneticamente, houve respostas significativas dessas variáveis às doses de B aplicadas.

O número de vagens por planta, que está diretamente relacionado com a produção (Santa Cecília et al., 1974), apresentou comportamento muito semelhante ao observado para a produção de MSGR (Figura 2). As doses de $B$ para produção do máximo número de vagens por planta foram estimadas de $2,67,2,70$, 2,64 e $2,54 \mathrm{mg}$ de $B \mathrm{dm}^{-3}$ para os solos GP, A, $\mathrm{GH}$ e $\mathrm{O}$, respectivamente.

$\mathrm{O}$ número de grãos por vagem $(\mathrm{Y})$, tal como as outras variáveis estudadas, mostrou uma relação raiz quadrática com as doses de $B$ aplicadas $(X)$, representada pela equação: $Y=$ $1,29+4,4995^{*} X^{0,5}-1,1985^{*} X\left(R^{2}=0,75\right)$. A dose de $B$ estimada para o máximo de GRVG foi de $3,5 \mathrm{mg} \mathrm{dm}^{-3}$. As maiores médias dessa variável foram verificadas para os solos $\mathrm{GH}$ e $\mathrm{A}$ (TABELA 4), confirmando o maior potencial desses solos para produção do feijoeiro. Andrade (1997), estudando essas mesmas classes de solos de várzea, verificou também que os solos $\mathrm{GH}$ e $\mathrm{A}$, quando adequadamente corrigidos e adubados, foram aqueles que proporcionaram o maior número de grãos por vagem do feijoeiro.

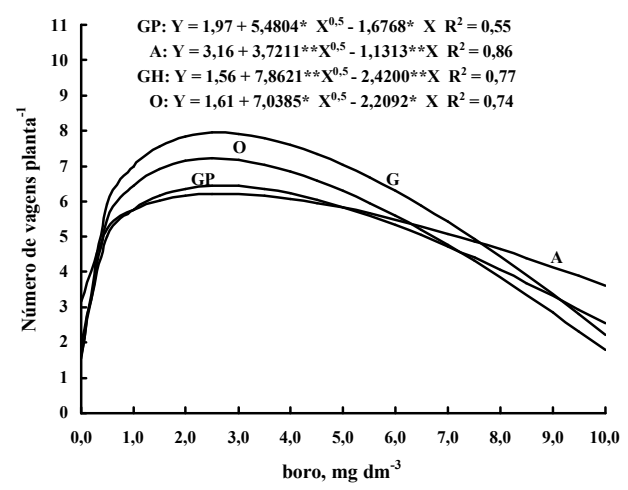

Figura 2 - Número de vagens por planta de feijoeiro em função das doses de B aplicadas aos solos de várzea ${ }^{* *},{ }^{*}$ significativo a $1 \%$ e $5 \%$, respectivamente pelo teste t).

TABELA 4 - Número de grãos por vagem (GRVG) do feijoeiro cultivado nos solos de várzea estudados (média de sete doses e quatro repetições).

\begin{tabular}{ll}
\hline Solo $^{1}$ & GRVG \\
\hline GP & $3,29 \mathrm{~b}$ \\
$\mathrm{~A}$ & $4,28 \mathrm{a}$ \\
$\mathrm{GH}$ & $4,58 \mathrm{a}$ \\
$\mathrm{O}$ & $3,62 \mathrm{~b}$ \\
\hline
\end{tabular}

${ }^{1} \mathrm{GP}=$ Glei Pouco Húmico, $\mathrm{A}=$ Aluvial, $\mathrm{GH}=$ Glei Húmico e $\mathrm{O}=$ Orgânico. Médias seguidas pela mesma letra não diferem entre si (Tukey, $5 \%$ ).

\section{CONCLUSÕES}

- Os solos estudados mostraram respostas significativas do feijoeiro à aplicação de boro.

- As doses de B suficientes para atingir $90 \%$ da produção máxima, produção máxima e causar redução de $10 \%$ na produção por toxidez, variaram entre os solos de 1,04 a 1,25; 2,50 a 2,83 e 4,54 a $5,33 \mathrm{mg} \mathrm{dm}^{-3}$ de solo, respectivamente.

- O potencial produtivo dos solos em ordem decrescente foi: Glei Húmico, Aluvial, Orgânico e Glei Pouco Húmico. 


\section{AGRADECIMENTOS} concedido.

Ao CNPq e FAPEMIG pelo financiamento

\section{REFERÊNCIAS BIBLIOGRÁFICAS}

ALVAREZ V., V.H.; NOVAIS, R.F. de; BRAGA, J.M.; NEVES, J.C.L.; BARROS, N.F.; RIBEIRO, A.C.; DEFELIPO, B.V. Avaliação da fertilidade do solo: metodologia. In: SIMPÓSIO DA PESQUISA NA UFV, 1., 1988. Viçosa. Resumos. Viçosa: UFV, 1988. p.68-69.

ANDRADE, C.A. de B. Limitações de fertilidade e efeito do calcário para o feijoeiro (Phaseolus vulgaris L.) em solos de várzea do sul de Minas Gerais. Lavras, 1997. 107p. Tese (Doutorado) - Universidade Federal de Lavras.

BATAGLIA, O.C.; RAIJ, B.van. Eficiência de extratores de micronutrientes na análise do solo. Revista Brasileira de Ciência do Solo, v.13, n.2, p.205-212, 1989.

BERGER, K.C.; TRUOG, E. Boron determination in soils and plants. Industrial and Engineering Chemistry, v.11, p.540-545, 1939.

BIGGAR, J.W.; FIREMAN, M. Boron adsorption and release by soils. Soil Science Society of America Proceedings, v.24, n.2, p.115-120, 1960.

BINGHAM, F.T.; PAGE, A.L.; COLEMAN, N.T.; FLACH, K. Boron adsorption caracteristics of selected amorphous soils from Mexico and Hawaii. Soil Science Society of America Proceedings, v.35, n.4, p.546-550, 1971.

BLAKE, G.R. Bulk density. In: BLACK, C.A. (Ed.) Methods of soil analysis: physical and mineralogical properties, including statistics of measurement and sampling. Madison: American Society of Agronomy, 1965. cap.30, p.374-390.

DAY, P.R. Particle fractionation and particlesize analysis. In: BLACK, C.A. (Ed.) Methods of soil analysis: physical and mineralogical properties, including statistics of measurement and sampling. Madison: American Society of Agronomy, 1965. cap.13, p.545-566.

ELRASHIDI, M.A.; O'CONNOR, G.A. Boron sorption and desorption in soils. Soil Science Society of America Journal, v.46, p.27-31, 1982.

EMPRESA BRASILEIRA DE PESQUISA AGROPECUÁRIA. Serviço Nacional de Levantamento e Conservação de Solos. Manual de métodos e análises de solos. Rio de Janeiro, 1979. 1v.
FAGERIA, N.K.; OLIVEIRA, I.P. de; DUTRA, L.G. Limitações químicas dos solos de cerrado e de várzea. In: EMPRESA BRASILEIRA DE PESQUISA AGROPECUÁRIA. Deficiências nutricionais na cultura ao feijoeiro e suas correções. Goiânia: EMBRAPA, CNPAF, 1996. p.8-11. (Documento, 65).

FAQUIN, V. Nutrição mineral de plantas. Lavras: ESAL/FAEPE, 1994. 227p.

GALRÃO, E.Z. Aplicação de micronutrientes e calcário no rendimento da soja em solo de várzea. Revista Brasileira de Ciência do Solo, v.14, n.3, p.381-384, 1990.

GUPTA, V.C. Relationship of total and hot-water soluble boron, and fixation of added boron, to properties of podzol soils. Soil Science Society of America Proceedings, v.32, n.1, p.45-48, 1968.

HATCHER, J.T.; BOWER, C.A.; CLARK, M. Adsorption of boron by soils as influenced by hidroxy aluminum and surface area. Soil Science, v.104, n.6, p.422-426, 1967.

HEILMAN, M.D.; CARTER, D.L.; GONZALES, C.L. The ethylene glycol monoethyl ether (EMEG) technique for determining soil surface area. Soil Science, v.100, p.409-413, 1965.

HINGSTON, F.J. Reactions between boron and clays. Australian Journal of Soil Research, v.2, n.1, p.83-95, 1964.

LOPES, A.S.; CARVALHO, J.G.de. Micronutrientes: critérios de diagnose para solo e planta, correção de deficiências e excessos. In: BORKERT, C.M.; LANTMANN, A. (Ed.) Enxofre e micronutrientes na agricultura brasileira. Londrina: EMBRAPA, CNPSO/IAPAR/SBCS, 1988. p.133-178.

MALAVOLTA, E. Elementos de nutrição mineral de plantas. São Paulo: Agronômica Ceres, 1980. $215 p$.

MALAVOLTA, E.; VITTI, G.C.; OLIVEIRA, S.A. Avaliação do estado nutricional das plantas: princípios e aplicações. 2.ed. Piracicaba: Associação Brasileira para Pesquisa da Potassa e do Fosfato, 1997. 319p.

MALCOLM, M.; PAGE, A.L.; BINGHAM, F.T. Adsorption interactions of monosilicic and boron acid on hydrous oxides of iron and aluminum. Soil Science Society of America Proceedings, v.36, n.3, p.510-514, 1972.

MARSCHNER, $H$. Mineral nutrition of higher plants. 2 ed. San Diego: Academic Press, 1995. 889p.

MEHRA, O.P.; JACKSON, N.L. Iron oxide removal from soils and clays by a dithionite-citrate system buffered with sodium bicarbonate. Clays and Clay Minerals, v.3, p.317-327, 1960.

OLSON, R.U.; BERGER, K.C. Boron fixation as influenced by $\mathrm{pH}$, organic matter content, and other factors. Soil Science Society of America Proceedings, v.11, n.5, p.216-220, 1946. 
PAULA, M.B.de; CARVALHO, J.G. de; SOARES, A.A.; NOGUEIRA, F.D. Avaliação da fertilidade de um solo de várzea (Glei Húmico) para a cultura do arroz. Pesquisa Agropecuária Brasileira, v.25, n.4, p.571-577, 1990

RAIJ, B.van.; CANTARELLA, H.; QUAGGIO, J.A.; FURLANI, A.N.C. (Ed.) Recomendações de adubação e calagem para o Estado de São Paulo. Campinas: Instituto Agronômico/Fundação IAC, 1996. 285p. (Boletim Técnico, 100).

RAIJ, B.van.; QUAGGIO, J.A.; CANTARELLA, H.; FERREIRA, M.E.; LOPES, A.S.; BATAGLIA, O.C. Análise química do solo para fins de fertilidade. Campinas: Fundação Cargil, 1987. 170p. RUSCHEL, A.P.; ROCHA, A.C. de M.; PENTEADO, A. de F. Efeito do boro e do molibdênio aplicados a diferentes revestimentos da semente de feijão (Phaseolus vulgaris L.). Pesquisa Agropecuária Brasileira, v.5, n.1, p.49-52, 1970.
SANTA CECÍLIA, F.C.; RAMALHO, M.A.P.; SILVA, C.C. Efeitos da adubação NPK na cultura do feijão (Phaseolus vulgaris L.) na zona sul de Minas Gerais. Agros, v.4, n.2, p.3-10, 1974.

SCHALSCHA, E.B.; BINGHAM, F.T.; CALINDO, G.C.; GALVAN, H.P. Boron adsorption by vulcanic ash soils in southern Chile. Soil Science, v.116, n.2, p.70-76, 1973.

VETTORI, L. Métodos de análise de solo. Rio de Janeiro: Ministério da Agricultura, 1969. 24p. (Boletim Técnico, 7).

Recebido para publicação em 01.12.98 Aceito para publicação em 18.08.99 